\title{
Implementation of an Embedded Sensor Based on Electrical Resistivity to Monitor Drying in Thick Concrete Structures
}

\author{
Joanna Badr ${ }^{1,2}$, Géraldine Villain ${ }^{2}$, Jean-Paul Balayssac ${ }^{1}$, Sérgio Palma Lopes ${ }^{2}$, Yannick \\ Fargier $^{2}$, Fabrice Deby ${ }^{1}$ and Sylvie Delepine-Lesoille ${ }^{3}$ \\ ${ }^{1}$ LMDC, Université de Toulouse, INSA/UPS Génie Civil, Toulouse 31077, France; badr@insa- \\ toulouse.fr, balayssa@insa-toulouse.fr, f_deby@insa-toulouse.fr \\ ${ }^{2}$ IFSTTAR, Site de Nantes, Bouguenais 44344, France; joanna.badr@ifsttar.fr, \\ geraldine.villain@ifsttar.fr, sergio.lopes@ifsttar.fr, Site de Bron, Bron 69675, France; \\ yannick.fargier@ifsttar.fr \\ ${ }^{3}$ Andra, French National Radioactive Waste Management Agency, Chatenay-Malabry 92298, France; \\ Sylvie.Lesoille@andra.fr
}

\begin{abstract}
Electrical resistivity is a parameter sensitive to several properties of concrete, including water content, which is one of the key parameters governing concrete long-term durability. In this paper, the monitoring of the concrete water content profile throughout its entire thickness is discussed using an electrical approach as a measurement method. This is very relevant to applications requiring a centimeter resolution over a large thickness. The aim of this paper is to implement a multi-electrode embedded sensor in a concrete slab to determine the resistivity profile over concrete depth in order to monitor its drying. The sensor, designed as a printed circuit board (PCB), is integrated in two $30 \mathrm{~cm}$ thick concrete slabs. Different measurement configurations are presented. Following qualification in laboratory and controlled conditions, the study focuses on characterizing the sensor's response during the drying of the slabs. The results demonstrate the capability of the sensor to monitor concrete drying by measuring the resistivity profiles with a spatial centimetric resolution.
\end{abstract}

Keywords: Electrical Resistivity, Embedded Sensor, Monitoring, Thick Concrete Structures, Drying Process.

\section{Introduction}

The durability of a concrete structure is characterized by its ability to keep the use functions for which it was designed. The main degradations of reinforced concrete structures are due to reinforcement corrosion, for which the parameter responsible for its development is the concrete water content.

The determination of the concrete water content using non-destructive testing (NDT) methods has been the subject of many studies (e.g. Balayssac and Garnier, 2017; Kaplanvural et al., 2018). Among these NDT methods, DC-electrical methods, which provide access to the electrical resistivity of the material, are particularly sensitive to the concrete water content (Millard, 1991; Andrade et al., 2007; Du Plooy et al., 2013; Fares et al., 2015). However, the electrical methods that are implemented on the surface have reduced resolutions with respect to the thickness of the concrete structures and the investigated depth does not generally exceed a few centimeters in the concrete cover. In addition, it is necessary to wet the surfaces of the electrodes to avoid high resistance contact. Hence, Badr et al. (2019) developed an embedded sensor based on a printed circuit board (PCB), which presents various advantages such as: 
measuring profiles with a centimeter resolution through the whole thickness of a reinforced concrete structure, ensuring good and lasting electrical contact between the concrete and the electrodes, reducing invasiveness, allowing a high geometric accuracy together with a low fabrication cost and mitigating wiring problems. This new resistivity embedded sensor and the measurement chain were validated in various solutions and in small concrete specimens $(\varnothing 11 \times 22 \mathrm{~cm})$ but not in full scale concrete structures (Badr et al., 2019).

The main aim of this study is thus to characterize the PCB sensor in more realistic operational conditions, namely two $30 \mathrm{~cm}$ thick reinforced concrete slabs, one reinforced with carbon steel bars (HA), and the other one with fiberglass rebars (an electrically insulating material) (FV). The variability of the measurements and the impact of the reinforcements are evaluated in order to test the sensitivity of the sensors by determining the electrical resistivity profiles as a function of the depth. The evaluation of the water content profile requires a material-dependent calibration procedure which is not presented in this article.

The paper starts with a description of the experimental program carried out on the slabs HA and FV each instrumented with two embedded PCB sensors. Then the characterization of the embedded sensors is presented regarding the repeatability, reproducibility and influence of the reinforeement. Finally, we discuss the monitoring of the resistivity profiles during 372 days of drying at $45^{\circ} \mathrm{C}$ and we conclude.

\section{Experimentall Program}
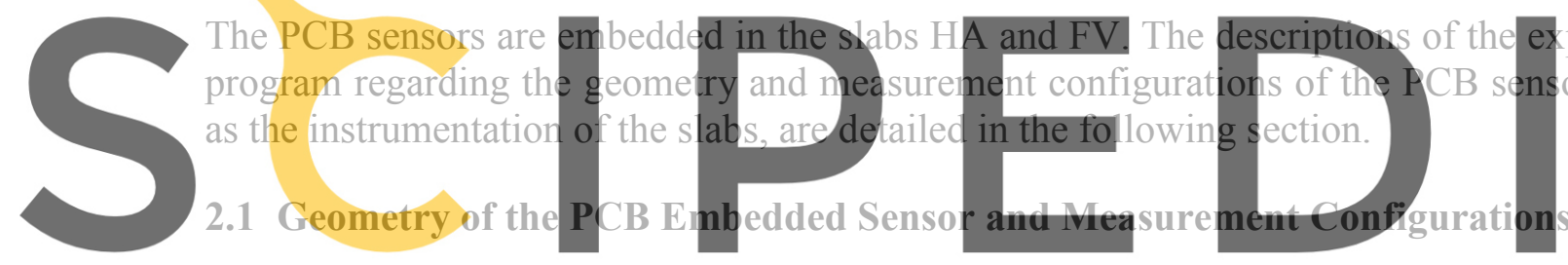

The PCB sensor has a ladder shape in order to improve the anchoring of the electrodes in the

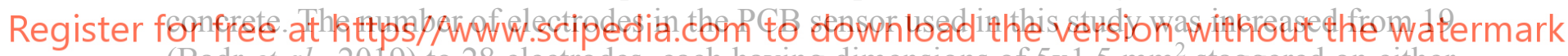

(Badr et al., 2019) to 28 electrodes, each having dimensions of $5 \times 1.5 \mathrm{~mm}^{2}$ staggered on either side of the circuit, to investigate the entire $30 \mathrm{~cm}$ thickness (Figure 1). The spacing between the electrodes is $2 \mathrm{~cm}$ on each side, hence $1 \mathrm{~cm}$ taking into account both sides.

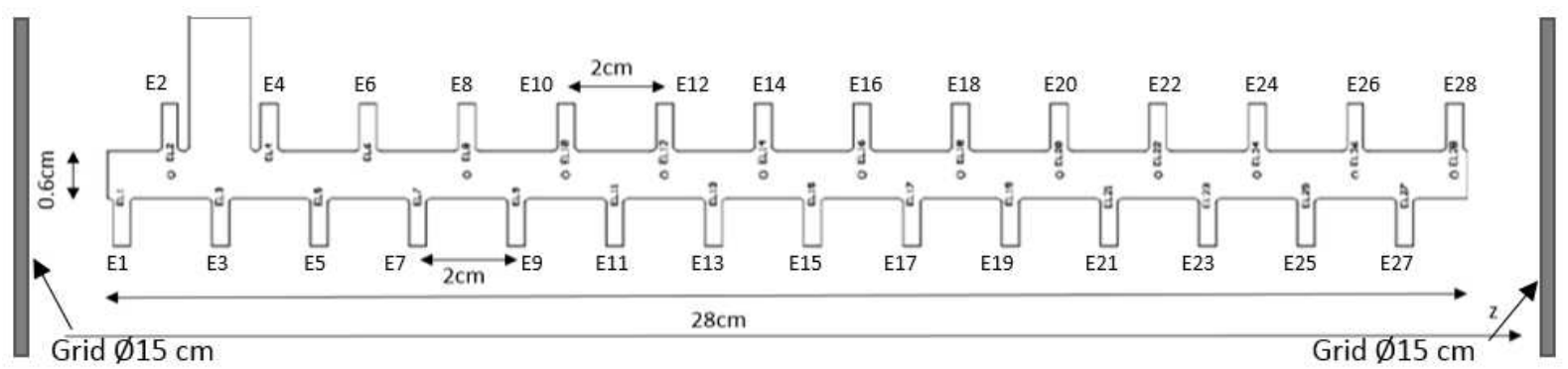

Figure 1. Schematic diagram of the PCB sensor with 28 electrodes.

The PCB sensor presents two measurement configuration modes: the Transmission configuration and the Wenner configuration. In the Transmission configuration mode, an electrical current of intensity $I$ is transmitted through the two stainless steel grids $(\varnothing=15 \mathrm{~cm})$ 
placed on both sides of the PCB sensor and a potential drop $(\Delta V)$ is measured between all pairs of consecutive electrodes located on the same side of the PCB sensor (E1E3, E2E4, E3E5, ..., E26E28) (Figure 1). In Wenner configuration mode, the quadrupole measurements C1C2P1P2 (where electrodes $\mathrm{C} 1$ and $\mathrm{C} 2$ are used for current injection and electrodes $\mathrm{P} 1$ and $\mathrm{P} 2$ are used for potential drop measurements) are successively E1E7E3E5, E2E8E4E6, E3E9E5E7, ..., E22E28E24E26 (Figure 1).

The apparent resistivity $\rho_{a}$ is obtained for each configuration, using equation (1):

$$
\rho_{a}=G \frac{\Delta V}{I}
$$

where $G$ (in meters) is a geometric factor which depends on the geometry of the structure and on the shape and positions of the electrodes. $G$ is numerically determined in a homogeneous medium by a finite element calculation using COMSOL Multiphysics ${ }^{\circledR}$.

\subsection{Slabs Instrumentation}

The concrete used in this study was based on cement type 1 (CEM I) with a water-cement ratio of 0.59 and a porosity of $15.0 \% \pm 0.9 \%$. Two concrete slabs measuring $75 \times 75 \times 30 \mathrm{~cm}^{3}$, equipped with $12 \mathrm{~mm}$ diameter reinforcement, spaced $20 \mathrm{~cm}$ apart, were cast. The cover concrete thickness is equal to about $5 \mathrm{~cm}$ so the distance between the two rebar beds is about $20 \mathrm{~cm}$. In one of the slabs the reinforcements are made of fiberglass (FV), and in the other the

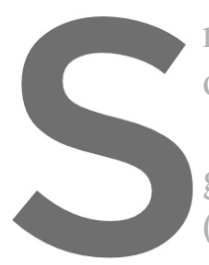
reinforcements are mad of the reinforcement di Two PCB sensors grids of diameter $15 \mathrm{~cm}$ (Eg) hand side relative
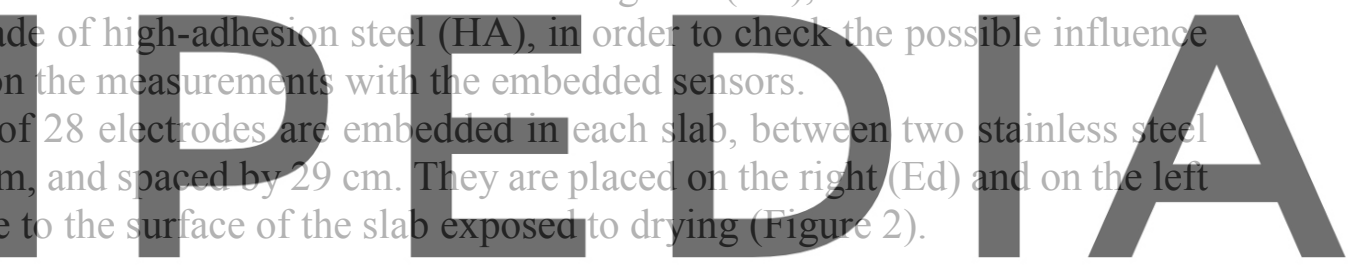

Register for free at https//www.scipedia.com to download the version without the watermark
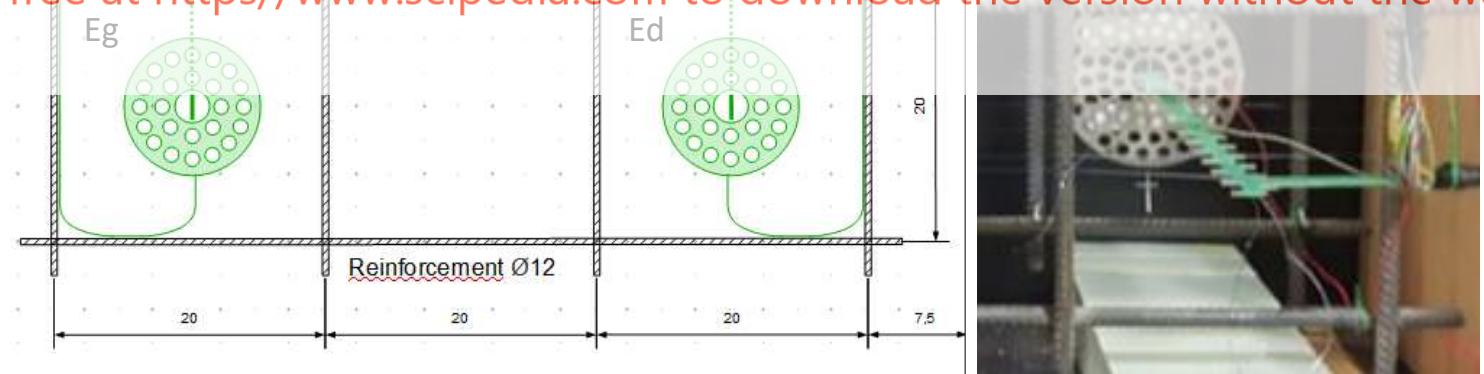

Figure 2. Instrumentation of the HA slab: (a) schematic diagram of the lower part of the slab where the PCB sensors Ed and Eg are placed (dimensions in $\mathrm{cm}$ ), (b) close-up photo on the PCB sensor Ed in the mesh reinforcement (with only one of the grids).

The slabs were conditioned during 41 days in wet cure in a room at a temperature $\mathrm{T}=20 \pm 2{ }^{\circ} \mathrm{C}$, and at a relative humidity $\mathrm{HR}=95 \pm 5 \%$. The method of generating the water content profile consists in inducing a unidirectional drying by exposing a single face to drying and waterproofing the other five faces by coating them with aluminum foil. The FV slab was exposed to 5 months of drying at $20^{\circ} \mathrm{C}$ and 1 year of drying at $45^{\circ} \mathrm{C}$ in order to accelerate the 
establishment of the resistivity profile. The HA slab was exposed to 13 months of drying at $20^{\circ} \mathrm{C}$ and 3 months of drying at $45^{\circ} \mathrm{C}$.

\section{Characterization of the PCB Sensors}

This part of our work examines the characterization of the PCB sensors embedded in the two reinforced concrete slabs HA and FV. First, we check the repeatability and reproducibility of the measurements made with each sensor, then we show the influence of reinforcement (HA and FV) by comparing the response of the sensors in the two slabs.

\subsection{Repeatability}

The evaluation of the repeatability of the apparent resistivity measurement is obtained by performing three measurements, repeated with few minutes interval. These measurements are acquired, under both saturated conditions (Table 1) and unsaturated conditions (Table 2), for a chosen electrode configuration, in the middle of the slab $(z=15 \pm 0.5 \mathrm{~cm})$, depending on the orientation of the sensor and the position associated with each configuration.

Table 1. Coefficient of variation $(\mathrm{CV})$ of apparent resistivity measurements at the initial saturated state t0 with the PCB sensors in the slabs HA and FV for both Transmission and Wenner configurations.
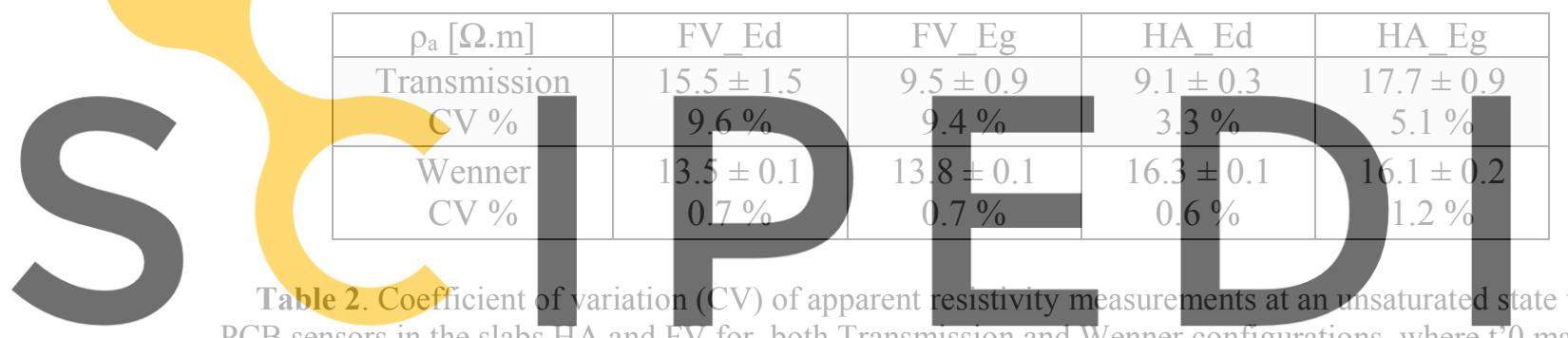

Table 2. Coefficient of variation (CV) of apparent
CB sensors in the slabs HA and $\mathrm{FV}$ for both Transinis

beginning of concrete drying at $45^{\circ} \mathrm{C}$

Register for free at https//www.scipedia.com to download the version without the watermark

\begin{tabular}{|c|c|c|c|c|}
\hline$\rho_{\mathrm{a}}[\Omega . \mathrm{m}]$ & $\mathrm{FV}$ Ed & FV Eg & HA Ed & HA Eg \\
\hline Transmission & $71.9 \pm 3.2$ & $69.9 \pm 4.1$ & $24.1 \pm 1.1$ & $8.7 \pm 0.8$ \\
CV \% & $4.5 \%$ & $5.9 \%$ & $4.6 \%$ & $9.2 \%$ \\
\hline Wenner & $103.5 \pm 0.6$ & $82.7 \pm 0.8$ & $12.6 \pm 0.2$ & $19.9 \pm 0.2$ \\
CV. \% & $0.6 \%$ & $1.0 \%$ & $1.6 \%$ & $1.0 \%$ \\
\hline
\end{tabular}

At the saturated state, the coefficient of variation $\mathrm{CV}$ for the repeatability ranged between $3.3 \%$ and $9.6 \%$ for the Transmission configuration and between $0.3 \%$ and $2.1 \%$ for the other configurations. At the unsaturated state, the CV varies between $4.5 \%$ and $9.2 \%$ for the Transmission configuration and between $0.5 \%$ and $2.1 \%$ for the other configurations. We note that the $\mathrm{CV}$ for the repeatability is consistently larger in the Transmission configuration. We recall that with this configuration, the current is injected through the metallic grids and the potential drop is measured between two consecutive electrodes of the PCB sensor. Therefore, a difference exists between the injection electrodes and the potential measurement electrodes concerning their size and the nature of the material that constitutes them. This may explain poorer repeatability compared to other configurations for which injection and potential 
measurement electrodes are identical. We have also verified that these CVs do not increase with the drying of the concrete which is promising for our application.

\subsection{Reproducibility Between PCB Sensors in the Right and Left Sides of Each Slab}

In this section, our goal is to evaluate the difference in response between the PCB sensors located on the right and left side of each slab (respectively denoted Ed and Eg). The reproducibility between the sensors is associated here with both the sensor change and the variability of the concrete material. We present the results obtained in the FV slab where the drying is more advanced to show the extreme states (saturated and unsaturated), knowing that similar behaviors are observed in the HA slab. Figure 3 shows the apparent resistivity profiles measured with both PCB sensors, Ed and Eg, using the Transmission configuration.

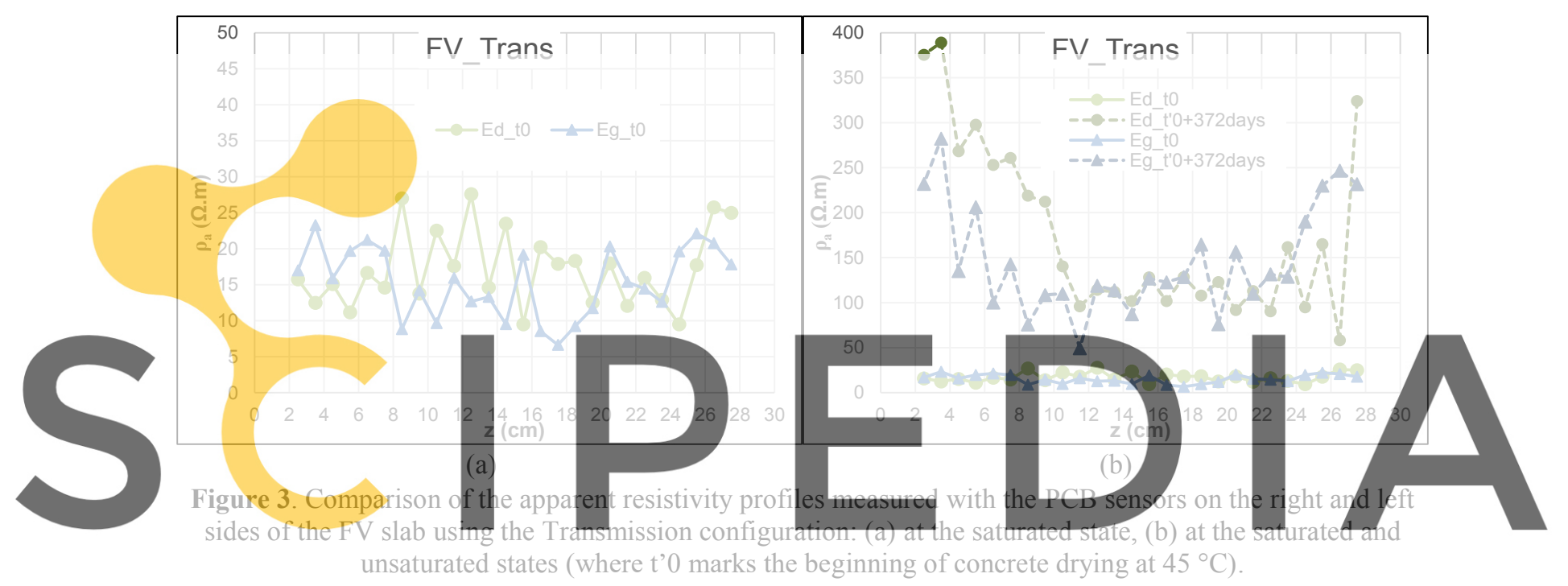

Register for free at https//www.scipedia.com to download the version without the watermark

The differences observed in Figure 3 can be related to the variability of the concrete. Indeed,

a measurement is essentialiy sensitive to a restricted volume of material between (and around) the two electrodes where the potential is measured (Badr et al., 2019). This volume is less than the representative elementary volume (REV) of an electrical measurement in concrete, the dimensions of the REV having to be at least three times the maximum size of aggregates (Du Plooy et al., 2013), in this case $3 \mathrm{Dmax}=36 \mathrm{~mm}$. At the scale of these very local measurements, the material cannot be considered homogeneous. Measurements are therefore expected to be sensitive to the natural variability of the material, and, in particular, to the distribution of aggregates in the immediate vicinity of the electrodes.

On the other hand, from the point of view of the global trends, the measurements exhibit the same evolution of the concrete water content between t 0 and $t^{\prime} 0+372$ days (Figure 3 (b)) on the left and right sides of the slab, which is also promising for our application. The reproducibility between both PCB sensors is therefore verified.

In the following, we only detail the results of the Ed sensors to simplify the presentation and interpretation. The measurements obtained from the Eg sensors are similar. 


\subsection{Influence of the Reinforcement}

The presence of steel reinforcement can disturb the electrical resistivity measurements, due to the fact that steel is a much better electrical conductor than the liquid phase in concrete. Various authors have cited the importance of steel's influence on the electrical resistivity measurement in a reinforced concrete structure (Millard, 1991; Polder et al., 2000; Bungey et al. 2006, Reichling et al., 2015; Alhajj et al., 2019; Villain et al., 2020).

In this section, we compare the response of the PCB sensors between the HA and FV slabs to evaluate the influence of the reinforcement. At the saturated state, the slabs HA and FV are similar in all aspects except that of the reinforcement nature, it is therefore relevant to make this comparison at this state. Figure 4 shows a comparison of the measurements obtained with the PCB sensors in the slabs HA and FV using the Transmission configuration.

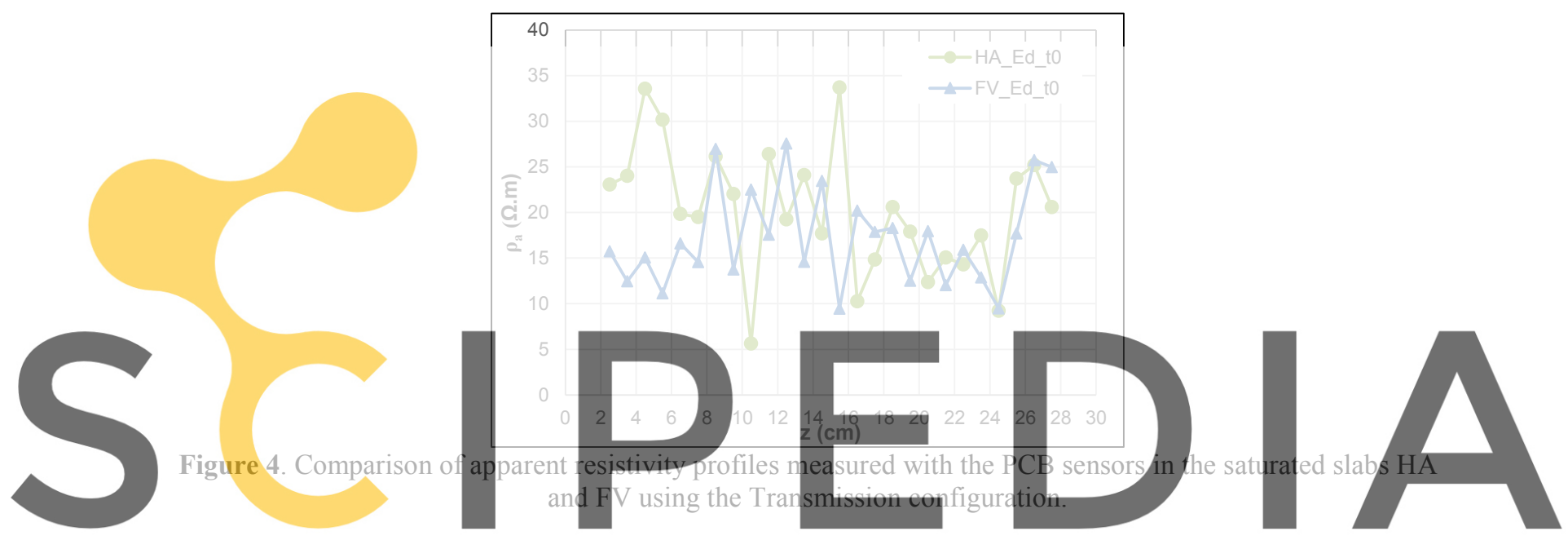

Differences between the sensors' responses in the two slabs are observed in Figure 4. At the

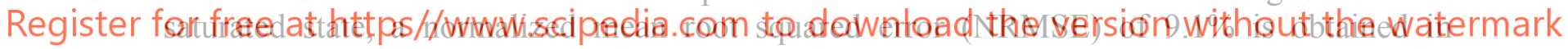
Transmission configuration between HA and FV, comparable to 8.4\% obtained, for the same configuration, between the PCB sensors on the right and on the left sides of the FV slab (section 3.2). Therefore, the difference in nature of the reinforcements (HA steel or FV fiberglass) has a small influence on the apparent resistivity measurements obtained by the PCB sensor placed in the center of the reinforcement mesh. Differences between the sensors' responses can be attributed to variations between the investigated materials in the two slabs.

Thus, in this study, the presence of steel reinforcements does not significantly affect the response of the PCB sensors.

\section{Monitoring of the Resistivity Profiles}

The purpose of this section is to study the apparent resistivity profiles of the PCB sensors during the drying of FV slab.

Due to the low resistivity gradient observed under drying at $20{ }^{\circ} \mathrm{C}$, and in order to test the sensitivity of the sensors to a higher gradient with depth, we accelerated the drying of the slabs by exposing them to an increased temperature of $45^{\circ} \mathrm{C}$. The variation of the apparent resistivity profile with time for the FV slab, using Transmission and Wenner configurations, is illustrated 
in Figure 5.

The monitoring carried out during the drying of the FV slab at $45{ }^{\circ} \mathrm{C}$ indicates a resistivity gradient between the surface exposed to drying $(\mathrm{z}=0 \mathrm{~cm})$ and the protected surface $(\mathrm{z}=30 \mathrm{~cm})$ revealing a lower saturation level at the surface, as we can observe in Figure 5. Near surface resistivity values $(\mathrm{z}=3 \pm 1 \mathrm{~cm})$ increase gradually during the 372 days of drying.

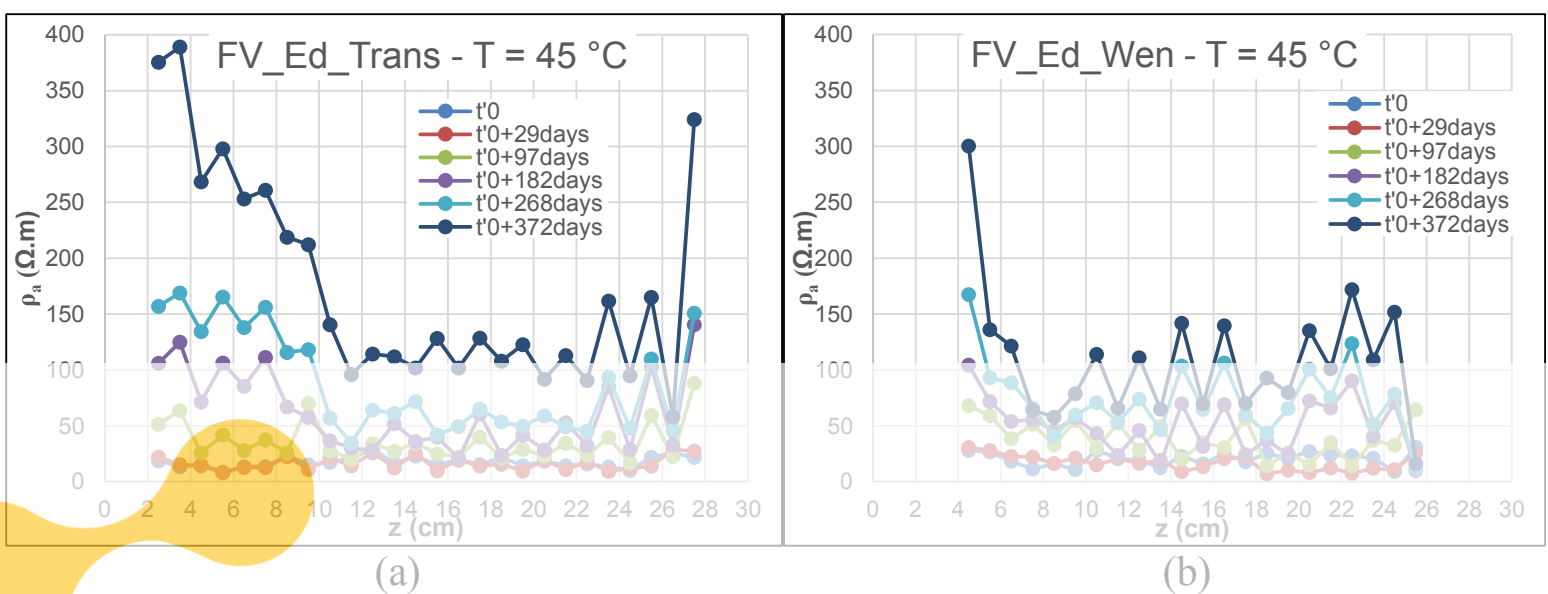

Figure 5. Monitoring of the apparent resistivity profiles measured with the PCB sensors during drying of the FV slab: (a) using the Transmission configuration, (b) using the Wenner configuration.

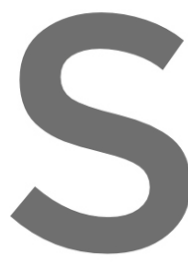

\section{Conclusion}

In this paper, a PCB

resistivity profile of two

bars (HA) and the other w
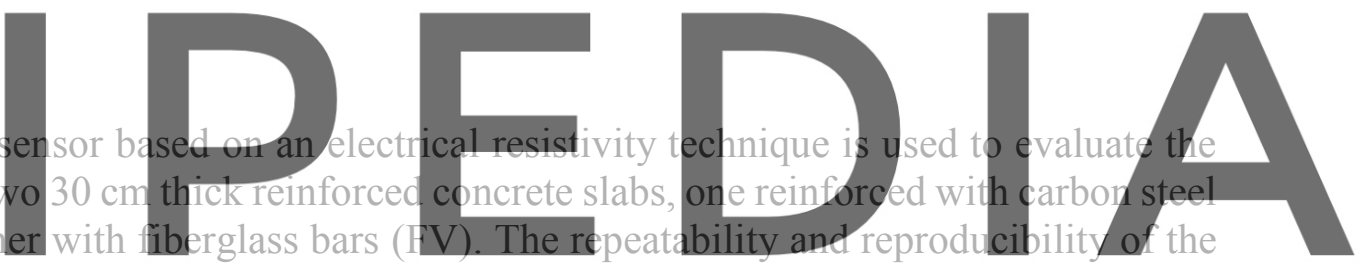

measurements are checked in saturated and unsaturated conditions, confirming that the results

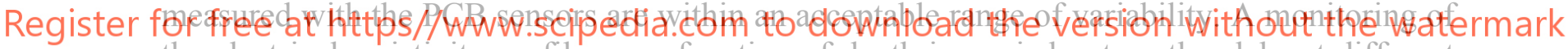
the electrical resistivity profiles as a function of depth is carried out on the slabs at different times of drying. Resistivity measurements increase over time, showing the sensitivity of the sensors to the evolution of concrete during drying. Thus, this new embedded sensor is validated in a real size reinforced concrete structure and we showed that it reaches its monitoring requirement with a centimetric resolution. In perspective, it is expected that the developed PCB sensor will be used in concrete structures to monitor water content profiles by means of a specific calibration.

\section{ORCID}

Joanna Badr: https://orcid.org/0000-0003-2607-2662

Géraldine Villain: https://orcid.org/0000-0002-4478-034X

Jean-Paul Balayssac: https://orcid.org/0000-0003-3965-4709

Sérgio Palma Lopes: https://orcid.org/0000-0001-7022-389X

Yannick Fargier: https://orcid.org/0000-0003-1139-6461

Fabrice Deby: https://orcid.org/0000-0002-6246-9192

Sylvie Delepine-Lesoille: https://orcid.org/0000-0002-9717-639X 
Joanna Badr, Géraldine Villain, Jean-Paul Balayssac, Sérgio Palma Lopes, Yannick Fargier, Fabrice Deby and Sylvie Delepine-Lesoille

\section{References}

Alhajj, M-A., Palma-Lopes, S. and Villain, G. (2019). Accounting for steel rebar effect on resistivity profiles in view of reinforced concrete structure survey, Construction and Building Materials, 223, 898-909. https://doi.org//10.1016/j.conbuildmat.2019.07.208.

Andrade, C., Polder, R. and Basheer, M. (2007). Non-destructive methods to measure ion migration. RILEM TC, 91-112.

Badr, J., Fargier, Y., Palma-Lopes, S., Deby, F., Balayssac, J.-P., Delepine-Lesoille, S. and Villain, G. (2019). Design and validation of a multi-electrode embedded sensor to monitor resistivity profiles over depth in concrete. Construction and Building Materials, 223, 321. https://doi.org/10.1016/j.conbuildmat.2019.06.226.

Balayssac, J.-P. and Garnier, V. (Eds.) (2017). Non-destructive testing and evaluation of civil engineering structures. Elsevier, Amsterdam, The Netherlands.

Bungey, J. H., Millard, S. G. and Grantham, M. G. (2006). Testing of concrete in structures (4th ed). Taylor \& Francis, New York, United States.

Du Plooy, R., Palma-Lopes, S., Villain, G. and Derobert, X. (2013). Development of a multi-ring resistivity cell and multi-electrode resistivity probe for investigation of cover concrete condition. NDT \& E International, 54, $27-36$.

Fares, M., Villain, G., Fargier, Y., Thiery, M., Derobert, X. and Palma-Lopes, S. (2015). Estimation of water gradient and concrete durability indicators using capacitive and electrical probes. International Symposium Non-Destructive Testing in Civil Engineering (NDT-CE 2015), 15-17 September 2015, Berlin, Germany, 9p.

Kaplanvural, İ., Pekşen, E. and Özkap, K. (2018). Volumetric water content estimation of C-30 concrete using GPR. Construction and Building Materials, 166, 141-146.

Millard, S. G. (1991). Reinforced concrete resistivity measurement techniques. Institution of Civil Engineers, March 1991, Liverpool, United Kingdom, 71-88.

Polder, R., Andrade, C., Elsener, B., Vennesland, Ø. methods for on site https://doi.org/10.1007

Reichling, K., Raupach, M. reinforced conerete structures using electrical resist
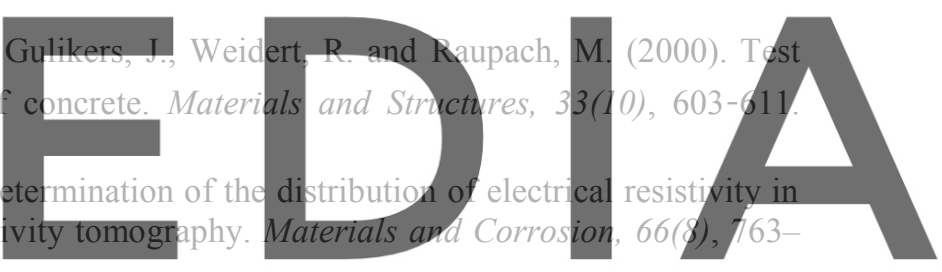
771.

Villain, G., Alhajj, M.-A., Palma-Lopes, S. and Bouteiller, V. (2020). Towards the Determination of Chloride

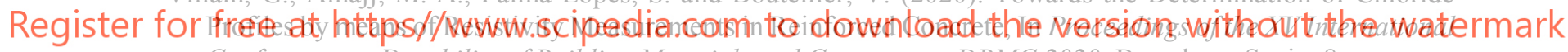
Conference on Durability of Building Materials and Components DBMC 2020, Barcelona, Spain, 8p. 